\title{
Unmanned Aerial Vehicle (UAV) based mapping in engineering geological surveys: considerations for optimum results
}

Tziavou, O. ${ }^{\text {a†, }}$ Pytharouli, S. ${ }^{a^{*}}$ and Souter J. ${ }^{\mathrm{b}}$

aDepartment of Civil and Environmental Engineering, University of Strathclyde, James Weir Building, 75 Montrose Street, Glasgow G1 1XJ, UK

${ }^{b}$ Survey Solutions Scotland, Bilston Glen Industrial Estate, 14 Dryden Rd, Loanhead EH20 9LZ, Scotland, $U K$

${ }^{*}$ Corresponding author: stella.pytharouli@strath.ac.uk

\section{Abstract}

UAVs have been used in engineering for at least two decades, mainly focusing on structural health monitoring, geological surveys and site inspections, especially at cases where a rapid assessment is required, for example after a natural disaster. While there is a wide range of recognition algorithms for the automatic identification of structural damage, structural geological features etc. from the acquired images, the parameters affecting the resolution of these images are often overlooked. As a result, the UAV technology is not used at its full potential and at times, it is even regarded as leading to poor outcomes. This paper discusses the main parameters affecting the resolution of the images acquired by a UAV. We present a case study of the structural geological mapping of a coastal area carried out using two types of UAVs: a fixed wing and a hexacopter. A comparison between the structural geological maps based on the orthophotos and one produced using conventional techniques shows that the level of detail is the same and the time spent is at least 5 times less when using a UAV. The fixed wing is faster and therefore, can cover large areas while the copter gives better resolution images as it can fly at lower heights. The latter is cost and time effective only if it is used for surveys limited to small areas. The characterization of some structural geological features has not been possible based solely on the orthophotos. We show that in order to achieve the desired accuracy, a ground sample distance of at least half that value is required. We discuss technical aspects, such as the effect of topography and UAV orientation on the overlap value, the camera calibration, number of control points and lighting conditions, that should be taken into account prior to flying a UAV and provide recommendations on how to obtain optimum results, i.e. orthophotos that suit the needs of the project.

Keywords: UAV, fixed wing, VTOL, mapping, image resolution, engineering geological survey

+ Deceased on $5^{\text {th }}$ March 2017 


\section{INTRODUCTION}

Unmanned Aerial Vehicles (UAVs) allow for the effective monitoring of large areas of land and existing infrastructure within a very short time compared to conventional techniques, a favourable characteristic, especially at cases where urgent intervention is required, e.g. when a natural disaster occurs, e.g. a rock slide (Greenwood et al., 2016; Tannant et al., 2017); 2016 Kaikura earthquake, New Zealand (Erickson, 2017), or when inspection is necessary but the site cannot be accessed due to Health and Safety concerns, e.g. 2011 Fukushima earthquake, Japan (Ackerman, 2011). The main principle is that a UAV takes aerial images, incorporated with spatial data based on GNSS and/or Inertial Measurement Unit (IMU), over an area to finally produce a high resolution 3D point cloud that can be used for a wide range of geological, civil/mining engineering applications and projects. The images are all processed to form a single image (mosaic) representing the area of interest. This image is geometrically corrected (orthomosaic) and georeferenced and can be used to extract information such as distances and locations, in the same way as a map.

UAVs have significantly developed during the last decades. They operate remotely in the form of small platforms carrying cameras and, for the majority of applications, are available as small or micro aircrafts or Vertical take-off and landing (VTOL) copters with four (quadcopters), six (hexacopters) or more propellers (Hackney and Clayton, 2015; Jordan, 2015). Currently, most of them are equipped with GNSS receivers and/or other sensors (e.g., Inertial System sensors, etc.). Telemetry facilities are frequently deployed for data transmission and/or management in almost real time when an immediate reaction is necessary (Jordan, 2015). The leading application of UAVs is undoubtedly 3-dimensional (3D) mapping, visualisation and modeling, thus contributing to applications such as topographic surveys, photogrammetric solutions, progress monitoring, disaster analysis, archaeological mapping, agriculture and forestry (e.g., Remondino et al, 2011; Niethammer et al., 2012; Draeyer and Strecha, 2014; Cryderman et al., 2015). A detailed discussion on the evolution of UAVs and the state of the art of this technology is given in a review work by Watts et al. (2012) and Colomina and Molina (2014). The latter conclude that the majority of commercial applications is supported by UAVs, the market of which is progressively developed: the UAV production, the civil/ commercial applications and the research on UAVs have increased by $68 \%, 78 \%$ and $55 \%$, respectively, between 2005 and 2013 (Colomina and Molina, 2014; Table 1, p. 80).

With the ever increasing use of UAVs there have been a number of studies focusing on the efficiency of UAVs in geotechnical, geological and other engineering applications. Siebert and 
Teizer (2014) used a UAV technology for the estimation of position errors and volume uncertainty estimation in construction and other civil engineering projects (e.g., roadworks, excavation, mining works, etc.). Error in heights was determined at the level of about $4 \mathrm{~cm}$ when the flight level was at $30 \mathrm{~m}$ and the difference in a volume of $440 \mathrm{~m}^{3}$ was found to be approximately $9 \%$ as compared to the figure obtained by conventional surveying using GPS. Similar results and techniques are also reported in Draeyer and Strecha (2014) for the determination of stockpile volumes and in Raeva et al (2016) for the case of mining in quarries. Engineering geology mapping surveys include detailed mapping of the outcrop, annotation of all features, names, dips and strikes that allow for the characterization of the site. UAVs can produce a very detailed image of the outcrop (e.g. Peng et al., 2017; Martínez-Martínez et al., 2017) but, in most cases, there is the need for someone to go on site for reconnaissance (Cawood et al., 2017). New developments on algorithms and image processing techniques permitted the automatic identification of types of rocks, faults, dip and strike measurements so manual work can significantly be reduced, e.g. Michlethwaite et al. (2012); Stumpf et al. (2013); Vasuki et al. (2014); Bemis et al. (2014).

Based on the reviewed literature, there are no easily accessible guidelines available regarding the choice of some of the parameters that greatly affect the quality of photos and consequently the orthomosaic obtained from a UAV e.g. overlap between photos, flight height, light conditions, specifications of the lens and camera, and weather conditions. As a result, if the user is not experienced or does not have a basic knowledge on surveying and photogrammetry (quite common considering the wide range of UAV user backgrounds), a poor quality orthomosaic is produced on which an automated image algorithm can do little. This frequently leads to the misconception that a poor outcome is always due to limitations of the UAV technology. This paper focuses on the use of UAVs for engineering mapping surveys and makes recommendations on the parameters that should be considered prior to flying a UAV in order to achieve optimum resolution of the obtained images. A case study on the mapping of structural geological features at an outcrop along the coast of South Ayrshire (Scotland) is also presented.

\section{PRINCIPLES OF PHOTOGRAMMETRY AND CHOICE OF FLIGHT PARAMETERS}

There are a number of technical parameters that need to be considered prior to flying a UAV: the required resolution of the orthophotos, the flight height, the overlap between the photos, the lens and camera characteristics. These parameters are important because they, not only 
103 affect the resolution of the obtained images, but also the time spent on site and the post104 processing time and effort for the production of the point cloud and the orthomosaic. In 105 addition, the resolution of the final orthomosaic significantly affects the amount of information 106 that can be extracted and any results obtained from the use of automatic feature detection 107 algorithms.

108 For engineering geological mapping surveys, a spatial resolution of less than $10 \mathrm{~cm}$ is generally 109 good. This translates to a requirement of maximum $10 \mathrm{~cm} /$ pixel, i.e. the Ground Sample 110 Distance (GSD, the distance on the ground between the centres of two adjacent pixels) should 111 be $10 \mathrm{~cm} /$ pixel or less. For a certain GSD, the flight height depends on the focal length $\mathrm{F}_{\mathrm{L}}$, the 112 sensor width $S_{w}$ and the number of pixels per photo width $\mathrm{P}_{\mathrm{N}}$ (He et al., 2012)

$$
F_{H}=G S D * F_{L} * \frac{P_{N}}{S_{W}}
$$

114 where

$115 \quad F_{H} \quad$ is the flight height $(\mathrm{m})$

116 GSD is the ground sample distance $(\mathrm{m})$

$117 \quad F_{L} \quad$ is the focal length (mm)

$118 \quad P_{N} \quad$ is the number of pixels per image width

$119 S_{w} \quad$ is the sensor width $(\mathrm{mm})$

120 From eq. 1 it is evident that keeping the flight height, number of pixels per image width and 121 sensor width the same and increasing the focal length, results in a better GSD, i.e. spatial 122 resolution. For example, for a flight height of $75 \mathrm{~m}$, a sensor width of $35.9 \mathrm{~mm}$ and 7360 number 123 of pixels per image width, a lens with $15 \mathrm{~mm}$ focal length gives a GSD of $2.4 \mathrm{~cm} /$ pixel. This value 124 becomes equal to $1.5 \mathrm{~cm} /$ pixel and $1 \mathrm{~cm} /$ pixel for a lens with focal length of $25 \mathrm{~mm}$ and $35 \mathrm{~mm}$, 125 respectively.

126 However, the GSD and the camera used are not the only parameters that should be considered 127 before choosing the flight height. Other factors to be accounted for are the flight time and the 128 number of images required to cover a specific area. Both depend on the overlap percentage, i.e. 129 the percentage of the same area on the ground covered by adjacent images as shown in Figure 130 1b. In general, an overlap value of more than $60 \%$ for the forward overlap and at least $20 \%$ for 131 the side overlap is considered adequate in photogrammetry in order for an orthomosaic to be 132 created. In practice, for UAVs, a higher overlap value, e.g. 80\%-85\%, would minimize the 133 possibility of gaps in the orthomosaic and is recommended (Campbell and Wynne, 2011). 134 However, it might not always be achievable due to camera triggering limitations and the flight 
135 parameters. For example, in the absence of wind, a UAV that flies at $23.5 \mathrm{~m} / \mathrm{s}$ equipped with a 136 camera that has a triggering limitation of $1 \mathrm{~Hz}$ will need a flight height at which $23.5 \mathrm{~m}$ 137 represents $20 \%$ of the along track image footprint to achieve an $80 \%$ forward overlap. For a 138 sensor size of $24 \mathrm{~mm}$ and a focal length of $35 \mathrm{~mm}$, it needs $175 \mathrm{~m}$ above ground level to achieve 139 an along track image footprint that lets the camera capture 80\% forward overlap. This flight 140 height might not allow for the desired image resolution. Furthermore, there might be additional 141 limitations, e.g. the maximum flight height in the UK is 500ft (approximately $152 \mathrm{~m}$ ) (Civil 142 Aviation Authority, 2016) which means that a flight height of $175 \mathrm{~m}$ is not permitted.

143 From trigonometry, the Ground distance $\mathrm{G}_{\mathrm{Dx}}$ (footprint perpendicular to the flight line) is 144 related to the flight height $F_{H}$, the focal length $F_{L}$ and the sensor width $S_{w}$ as (see Figure 1 a for 145 reference)

$$
\mathrm{G}_{\mathrm{Dx}}=\left(\mathrm{F}_{\mathrm{H}} / \mathrm{F}_{\mathrm{L}}\right) * \mathrm{~S}_{\mathrm{w}}
$$

147 Similarly the Ground distance $\mathrm{G}_{\mathrm{Dy}}$ (footprint along the flight line) is given by

$$
\mathrm{G}_{\mathrm{Dy}}=\left(\mathrm{F}_{\mathrm{H}} / \mathrm{F}_{\mathrm{L}}\right) * \mathrm{~S}_{\mathrm{L}}
$$

149 where $\mathrm{S}_{\mathrm{L}}$ is the sensor size in the direction perpendicular to the flight line.

150 The flight line spacing $F_{L S}$ (Figure $1 \mathrm{~b}$ ) is fiven by

$$
\mathrm{F}_{\mathrm{LS}}=\mathrm{G}_{\mathrm{Dx}} * \text { (1-side overlap) }
$$

152 while the number of flight lines $\mathrm{N}_{\mathrm{FL}}$ is equal to

$$
\mathrm{N}_{\mathrm{FL}}=\mathrm{W} / \mathrm{F}_{\mathrm{LS}}
$$

154 where $\mathrm{W}$ is the width of the surveyed area.

155 The distance between the images $D_{i}$ is given by

The number of images per flight line of length $\mathrm{L}$ is

and the total number of images per flight is equal to

$$
\mathrm{N}_{\mathrm{Ti}}=\mathrm{NFL}^{*} \mathrm{~N}_{\mathrm{i}}
$$


(a)

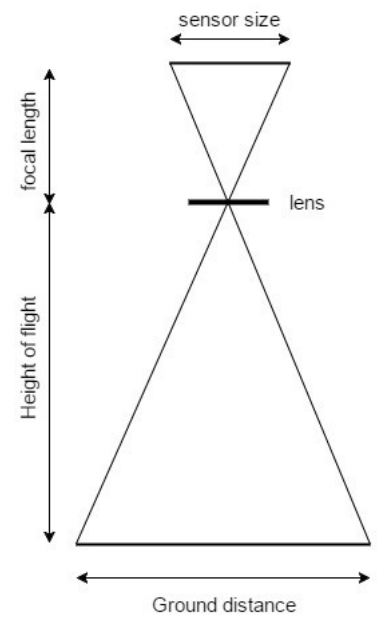

(b)

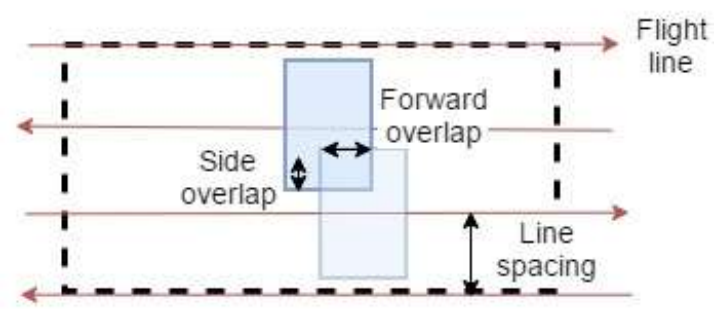

Figure 1 (a) Schematic diagram (not in scale) showing the relationship between the flight height, the focal length, the sensor size and the ground distance. (b) Schematic representation of the flight lines (red solid arrow lines) above the area of interest (dashed line) the forward and side overlap and the flight line spacing. The blue rectangles represent the footprint of images on the ground. Figure not in scale.

162 For example, the Sony A7R camera has a sensor size $39.5 \mathrm{~mm} \times 24 \mathrm{~mm}$. If the area to be surveyed

163 is $200 \mathrm{~m} \times 100 \mathrm{~m}$, using a lens with a focal length of $15 \mathrm{~mm}$ and a flight height of $75 \mathrm{~m}$ would result

164 in a ground distance (footprint) for each photo of $197.5 \mathrm{~m} \times 120 \mathrm{~m}$ (equations (2) and (3)

165 respectively). The spacing between the flight lines for an overlap of $80 \%(0.8)$ is $39.5 \mathrm{~m}$ (eq.4)

166 and the number of flight lines required for an area of width $100 \mathrm{~m}$ is 3 (rounded up from eq.5).

167 The distance between the images is $24 \mathrm{~m}$ (eq.6) and the number of images per flight line (length

168 equal to $200 \mathrm{~m}$ ) is 11 (rounded up from eq.7). This brings the total number of acquired images

169 for this area to 33 (eq.8).

170 For the Sony A7R camera (mounted on Trimble UX5 HP fixed wing) Figure 2 summarises how

171 the GSD, the flight time and the number of acquired images change with the flight height and the focal length (lens) for an area of $1 \mathrm{~km} \times 1 \mathrm{~km}$. Numbers in Figure 2a and c have been calculated using eq.(1) -(8) while Figure 2 b numbers were calculated using the Trimble Flight

174 Calculator (http://uas.trimble.com/calculator).

175 From Figure 2 it is evident that the focal length of the camera plays a significant role on the 176 flight height as it can result in the same or even better resolution at twice the flight height to 177 the one achieved by a lens with a smaller focal length (Figure 2a). Choosing a higher flight height reduces the flight time (Figure $2 \mathrm{~b}$ ) and the post-processing time since the number of acquired

179 images covering the same area is significantly smaller.

180 When the camera and focal length (lens) do not change, the impact of the flight height on the 181 image resolution, the flight time and number of images is more prominent. Figure 3(a) and (b) 182 show the effect of the flight height on the change of the GSD, the number of images acquired and 
the flight time (calculated using the Trimble Flight Calculator) for a survey area of $1 \mathrm{~km}^{2}$ and $0.01 \mathrm{~km}^{2}$, respectively. The results refer to an Olympus E-PL7 camera with a $14 \mathrm{~mm}$ lens, compared to those for the fixed wing.

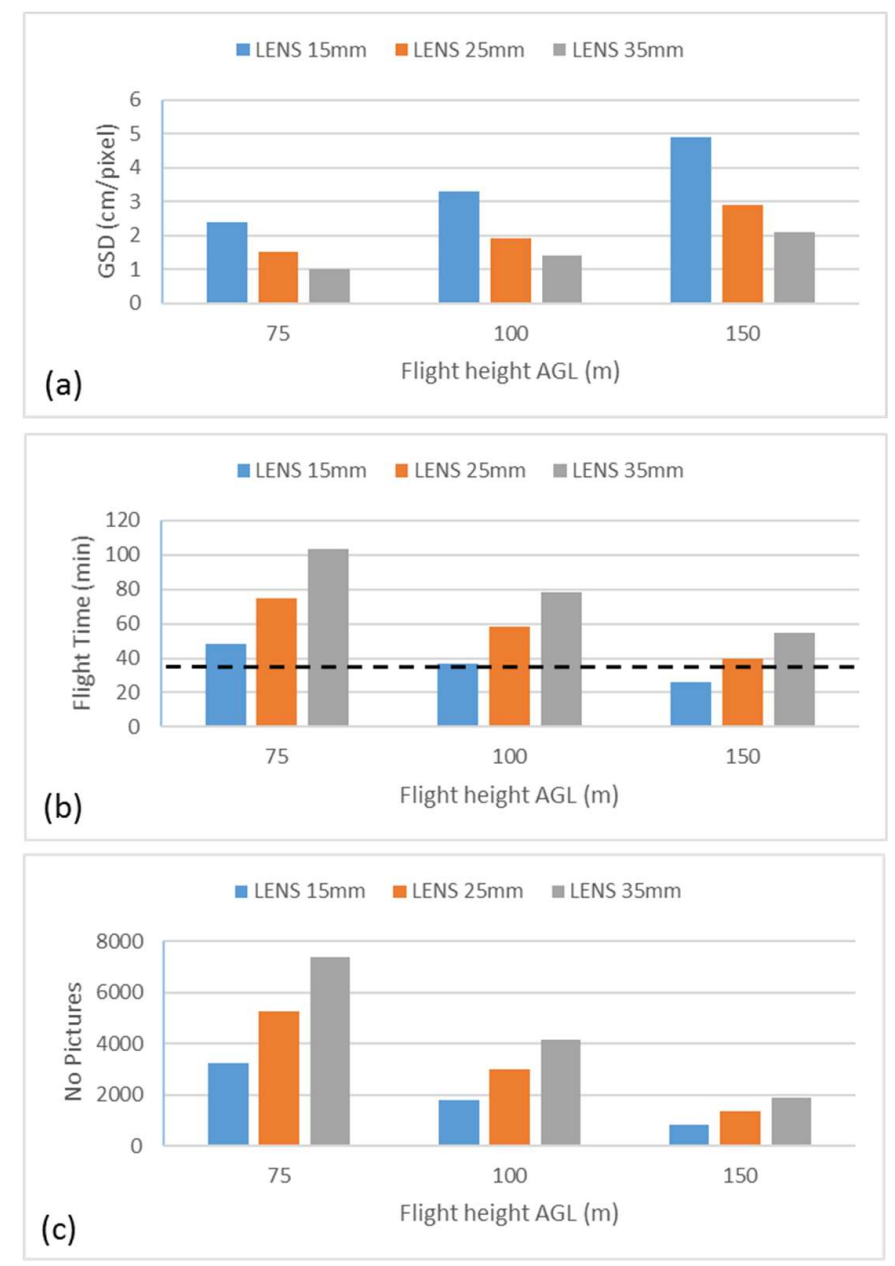

Figure 2 Change of (a) the GSD, (b) the flight time and (c) the number of acquired images with the flight height and the focal length (lens) for a survey area of $1 \mathrm{~km} \times 1 \mathrm{~km}$ as obtained for the Sony A7R camera mounted on Trimble UX5 HP (fixed wing). The dashed horizontal line in (b) denotes the threshold of 35 mins which is the maximum time per flight for the UX5 HP.

As can be seen from Figure 3a, the resolution of the images (GSD value) could be better than $0.1 \mathrm{~cm} /$ pixel, however, this would require 326 flights (or at least 4.5 days for a maximum time of 20 minutes per flight for the ZX5). Even if the flight time was acceptable, the total number of acquired images $(\sim 1,550,000)$ would have made the post-processing impossible. A relatively manageable number of images, i.e. less than 8,000, for a commonly used computer, would translate to a flight height of $75 \mathrm{~m}$ or less for a $1 \mathrm{~km}^{2}$ survey area. But the required flight time is still quite high at $435 \mathrm{~min}$ (more than 7 hours) resulting in the need of 22 flights. Even at a flight height of $150 \mathrm{~m}$, the required number of flights to cover the $1 \mathrm{~km}^{2}$ area would be 10 . 
195 These numbers reduce by at least 2 orders of magnitude if the area to be surveyed is smaller as shown in Figure 3(b). While the value of the GSD does not change for the same flight height between Figure 3(a) and Figure 3(b), the differences in the required flight times and number of acquired images are significant. An area of $0.1 \mathrm{~km} \times 0.1 \mathrm{~km}$ can be surveyed with a single flight

199 (16 minutes) at 25m flight height, resulting in a GSD value smaller than $1 \mathrm{~cm} /$ pixel.

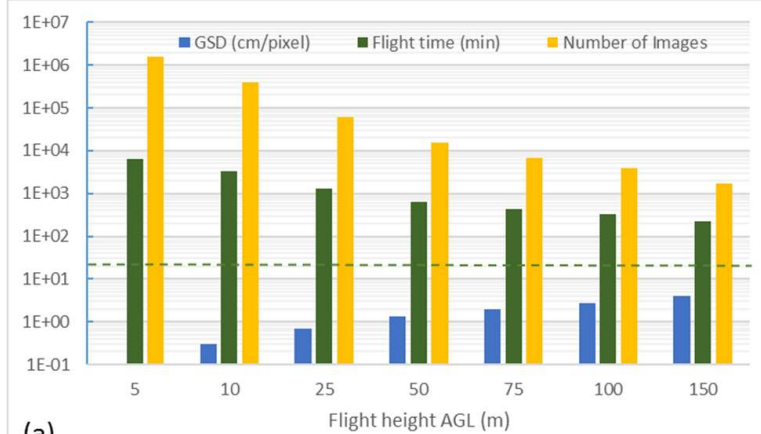

(a)

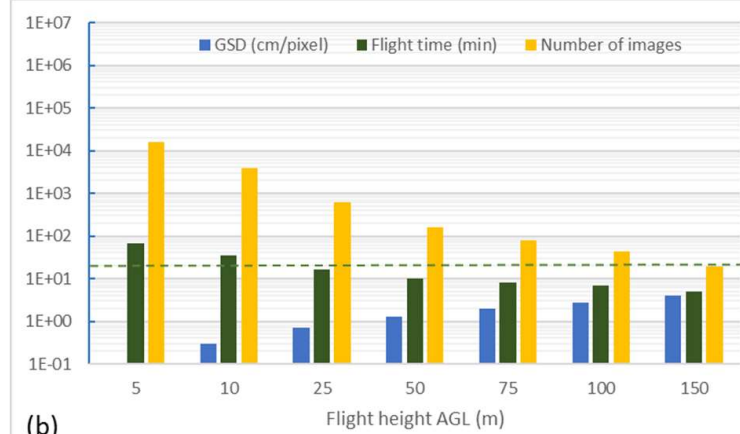

(b)
Flight height AGL (m)

Figure 3 Change of the GSD (blue), the flight time (green) and the number of acquired images (yellow) with the flight height for an area of (a) $1 \mathrm{~km} \times 1 \mathrm{~km}$ and (b) $0.1 \mathrm{~km} \times 0.1 \mathrm{~km}$. The focal length (lens) is $14 \mathrm{~mm}$ and the camera used is the Olympus E-PL7 mounted on Trimble ZX5 (hexacopter). The dashed horizontal line denotes the threshold of 20 mins which is the maximum time per flight for the ZX5. Note that the y-axis for both plots is in logarithmic scale.

200 The choice in the range of values used for the flight height in Figure 2 and 3 was dictated by 201 aviation regulations. In the UK, the maximum flight height above ground level (AGL) and the 202 maximum horizontal distance from the person in charge are defined by the Civil Aviation 203 Authority (CAA) as $122 \mathrm{~m}$ (400ft) and 500m (Visual Line Of Sight, VLOS ) and 152m (500ft) and $204750 \mathrm{~m}$ (Extended VLOS, EVLOS), respectively. In other European countries the flight height is $205150 \mathrm{~m}$, in the US it is $400 \mathrm{ft}(122 \mathrm{~m})$. There are also limitations due to the UAV technology itself. 206 For example, for the fixed wing and the hexacopter used in this study, the minimum flight height 207 is $75 \mathrm{~m}$ and $20 \mathrm{~m}$ (for an autonomous flight), respectively.

3. CASE STUDY: STRUCTURAL GEOLOGICAL MAPPING OF A SEDIMENTARY OUTCROP IN 209 SOUTH AYRSHIRE (SCOTLAND) 
210 We tested the UAV technology on a project demanding high resolution: the structural geological 211 mapping of a fault zone outcrop in Scotland's south-west coast. The field area is located on 212 Whitehouse Shore, a rocky beach a few miles south of the town of Girvan, South Ayrshire. The 213 outcrop has well exposed sedimentary and structural geological features (Figure 4) and is 214 located within an Ordovician inlier in the Midland Valley Terrane (McCay, 2014). The area has 215 been mapped in detail as part of previous projects (Lawson and Weedon, 1992; McCay, 2014) 216 and therefore, constituted a favourable site that allowed for comparisons between the 217 previously generated maps from conventional geological mapping surveys and maps generated 218 as part of this case study based solely on orthomosaics.

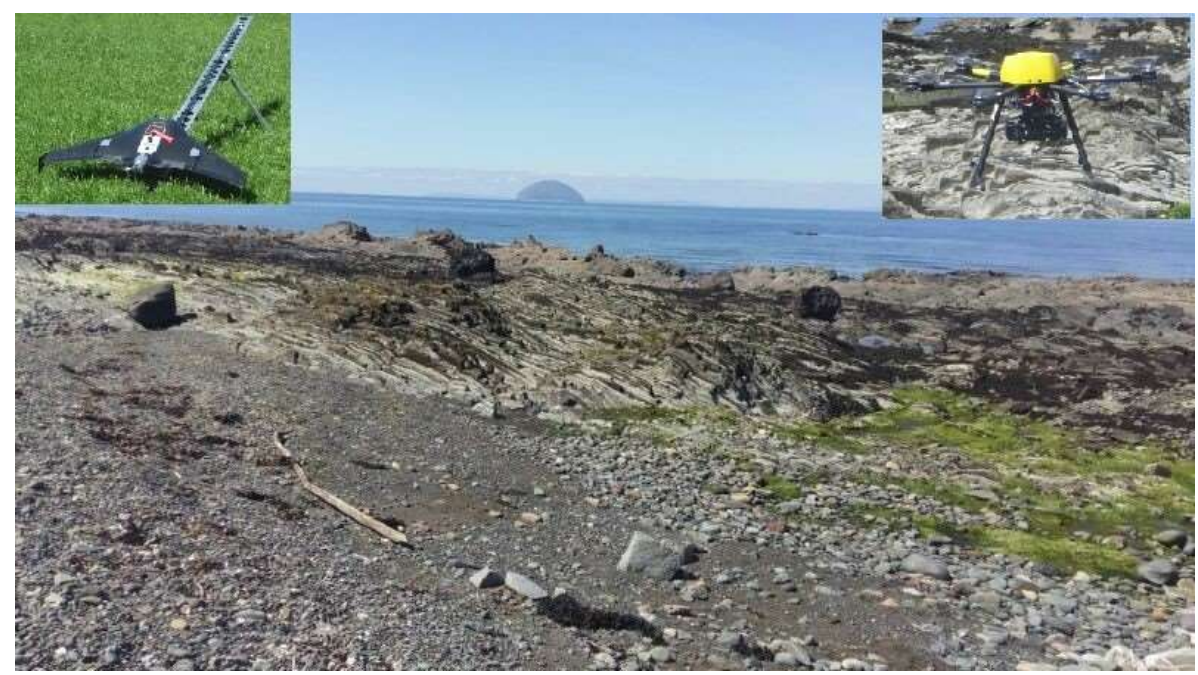

Figure 4 The outcrop along Whitehouse Shore, South Ayrshire, Scotland. Inset left: the UX5 HP. Inset right: the ZX5 hexacopter.

219 The UX5 HP (fixed wing) and ZX5 (hexacopter) of TRIMBLE were used for the data collection 220 for this case study (Figure 4inset). Their main technical characteristics are provided in Table 1.

Table 1. Main technical characteristics of TRIMBLE UX5 HP and ZX5

\begin{tabular}{|l|l|l|}
\hline \multicolumn{1}{|l|}{} & UX5 HP & ZX5 \\
\hline Type & Fixed Wing & Rotary Wing \\
\hline Dimensions & $100 \times 65 \times 10.5 \mathrm{~cm}$ & $85 \times 49 \mathrm{~cm}$ \\
\hline Camera & Sony A7R, 36 MP & Olympus E-PL7, 16 MP \\
\hline Image dimensions & $7360 \times 4912$ pixels & $4608 \times 3456$ pixels \\
\hline Focal length & $15 \mathrm{~mm}$ & $14 \mathrm{~mm}$ \\
\hline Sensor size & $39.5 \mathrm{~mm} \times 24 \mathrm{~mm}$ & $17.3 \mathrm{~mm} \times 13 \mathrm{~mm}$ \\
\hline
\end{tabular}

For the field measurements, two flights were planned using the UX5 HP and the ZX5 copter. Table 2 summarises the parameters considered for the flight plan. 
Table 2. Flight plan parameters for the Whitehouse Shore outcrop survey.

\begin{tabular}{|l|c|c|}
\hline & UX5 HP & ZX5 \\
\hline Flight height $\mathrm{F}_{\mathrm{H}}(\mathrm{m})$ & 79 & 30 \\
\hline Area length, $\mathrm{L}(\mathrm{m})$ & $120^{*}$ & $56^{*}$ \\
\hline Area width, $\mathrm{W}(\mathrm{m})$ & $55^{*}$ & $64^{*}$ \\
\hline Forward overlap (\%) & 87 & 89 \\
\hline Side overlap (\%) & 87 & 89 \\
\hline
\end{tabular}

*These are nominal dimensions as the actual shape of the areas surveyed with the UX5 HP and ZX5 was not rectangular.

The field measurements at Whitehouse Shore lasted about four hours including necessary work prior to the flights on the establishment of five control points along the beach. The take off of the UX5 HP took place at a location approximately 500m away from the beach. The flight lasted 8 minutes. The flight with the ZX5 lasted approximately 14 minutes. The take off and landing took place directly on the beach area. Figure 5(a) and (b) show the final orthomosaics obtained from the UX5 HP and ZX5, respectively.

Using the orthomosaics and software 'Trimble Business Centre, TBC', two structural geological maps were produced and presented in Figure 7Figure 6 and Figure 6Figure 7. These maps contain the main geological formations of the area under consideration, such as thrust faults, strike-slip faults, fractures, joints and other geological structures. Several thrust faults (shown as red dashed lines in Figure 7Figure 6 and Figure 6Figure 7, respectively) have been recognised over the field site. Another significant geological feature of the field site, clearly observed and delineated, is the middle or main strike-slip fault also shown in the maps. It is represented by a thick red line labelled "Main Fault Gully". Also, a splay is illustrated close to the main strike-slip fault showing almost the same direction. The main-strike slip fault contains an extensive uncemented brecciated zone which is composed by pebbles and sand (blue area in Figure 7Figure 6 and Figure 6Figure 7). This zone is also present near the splay fault and is labelled "covered zone". The covered zone is surrounded by two rocks; red mudstone and green mudstone (shown as grey and green area, respectively, in Figure 7Figure 6 and Figure 6Figure 7). Sandstone bands are observed along the red mudstone. Furthermore, a series of joints and shear fractures are clearly detected mainly around the strike-slip fault. Shear fractures are primarily characterised over the study area by their small scale offsets of the sandstone bands and thrust faults, as it is also reported in McCay (2014). Shear fractures are quite different from the strike-slip faults not only concerning their smaller offset but also due to their simple composition. Two typical cases of shear fractures labelled as 'Fracture with Green Halo' and 
257 'Carbonate Vein' were observed. The colour and resolution of the images did not allow for the 258 characterization of other visible fractures and joints (labelled as 'Unidentified Fractures').

259

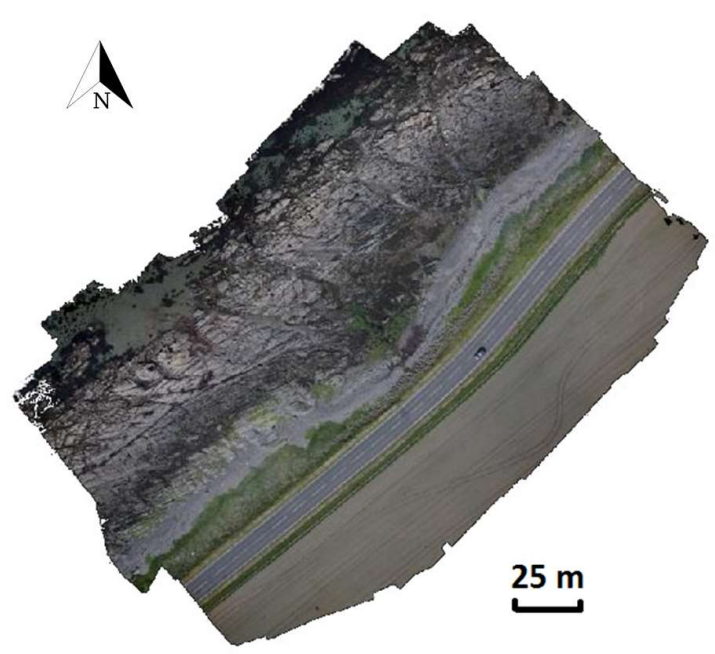

(a)

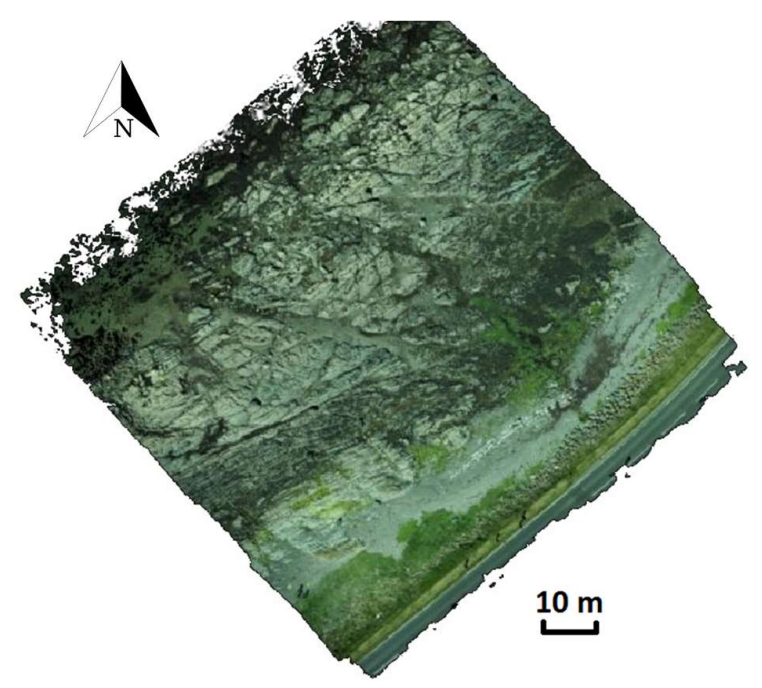

(b)

Figure 5 Orthorectified photos from the surveyed area (a) by the UX5 HP and (b) by the ZX5. 


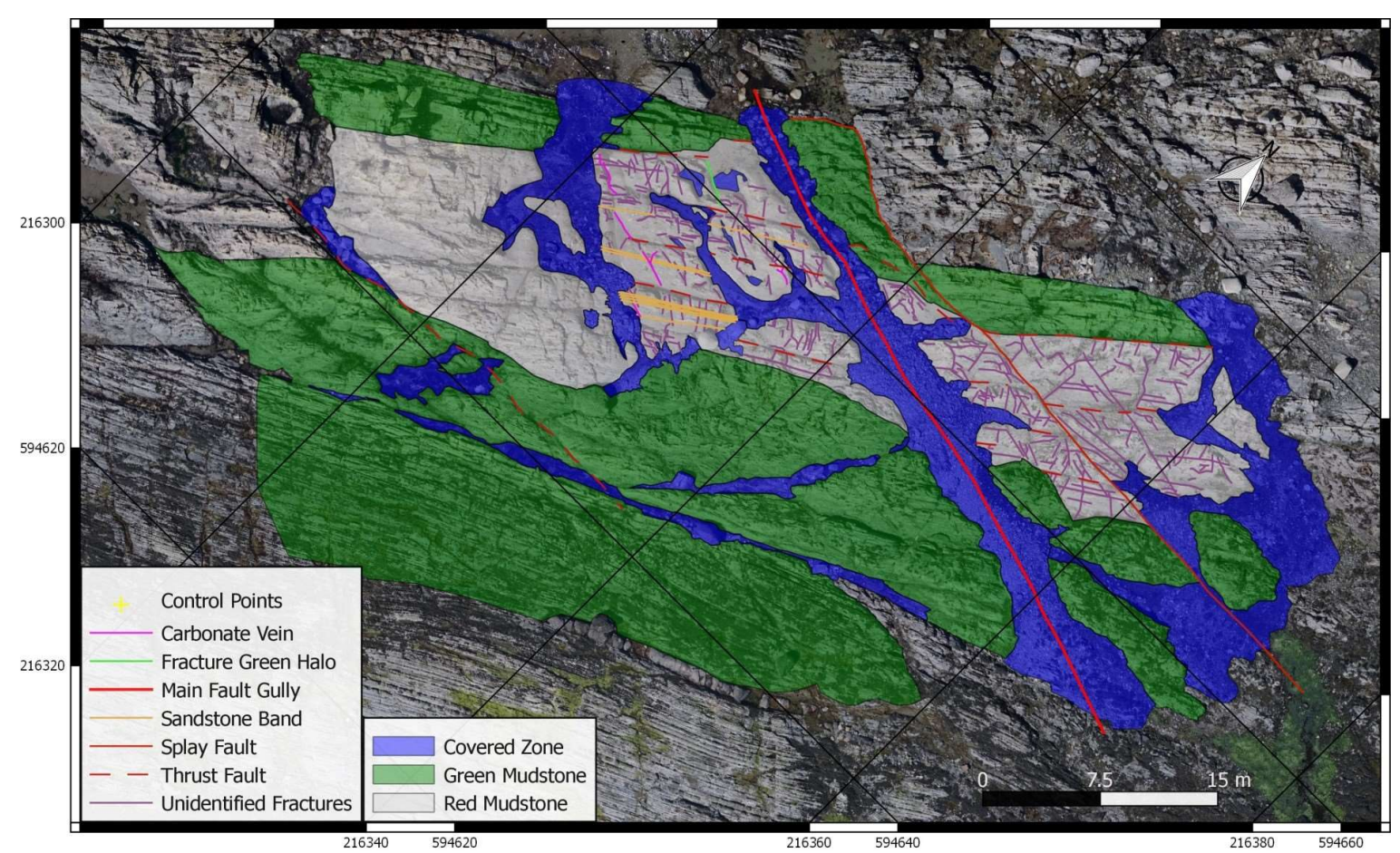

Figure 76 Detailed georeferenced map of the surveyed area using the UX5 HP showing the distribution and locations of the geological structural features. The map is overlayed on the orthomosaic from the images obtained by the UX5 HP.

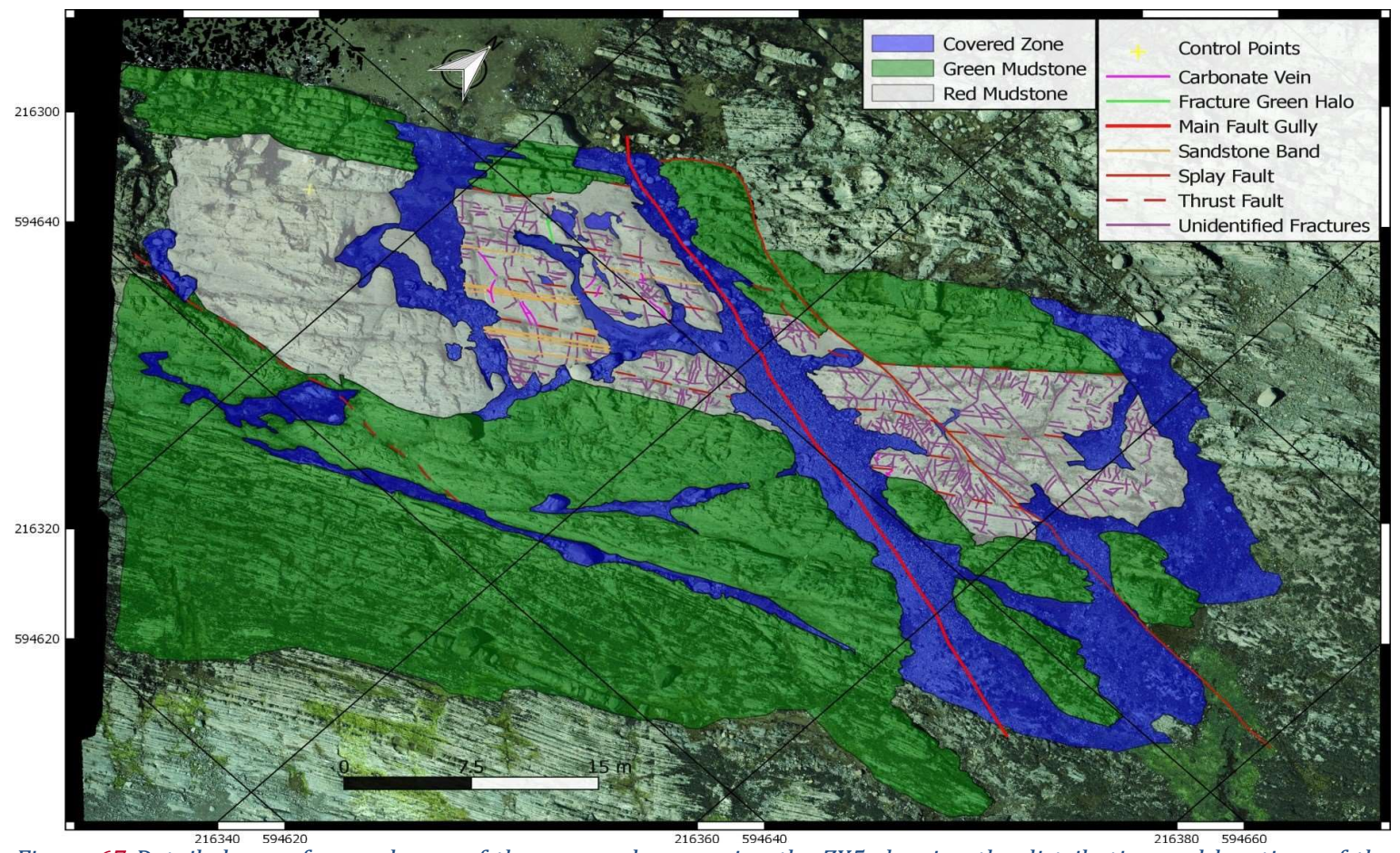

Figure 67 Detailed georeferenced map of the surveyed area using the ZX5 showing the distribution and locations of the geological structural features. The map is overlayed on the orthomosaic from the images obtained by the ZX5.

260 Due to the lower flight height and lower speed ( $3 \mathrm{~m} / \mathrm{sec}$ as opposed to $23.5 \mathrm{~m} / \mathrm{sec}$ for the UX5

261 HP) the map produced using the ZX5 orthomosaic is more detailed compared to the map from

262 the UX5 HP. According to the theoretical GSD value for the ZX5, i.e. $0.8 \mathrm{~cm} /$ pixel, we should have 
263 been able to distinguish objects that (1) have a length or width of at least 8mm or more, and (2) $\$ 64$ are $8 \mathrm{~mm}$ apart or more. On the SW part of the surveyed area shown in Figure 6Figure 7 the geological formation of green mudstone covers a larger area than that of Figure 7Figure 6 due to the high resolution of ZX5 that made possible to identify the limit of the green mudstone in the orthomosaic. This was not possible to achieve in the orthomosaic of UX5 HP where the limits 268 of the formation were not distinct. In addition, in the area covered by red mudstone (NE area), $\$ 69$ more fractures are detected in the map based on the ZX5 orthomosaic (Figure 6Figure 7) compared to those in the map based on the UX5 HP orthomosaic (Figure 7Figure 6) despite the fact that for the vast majority of them, their nature remains unidentified on both maps.

272 In an attempt to determine some of the main geometrical characteristics, i.e. width and length, 273 of the structural geological features that were identified in the orthomosaics, we selected a well274 defined joint (Figure 8a). Its length and width were measured in the field and found equal to $2750.936 \mathrm{~m}$ and $0.034 \mathrm{~m}$, respectively. The length was measured using a measuring tape. The error 276 of these measurements was within $1 \mathrm{~mm}$. The determination of both the width and the length 277 of the joint using exclusively the orthomosaic was not straight forward. Although, the GSD value
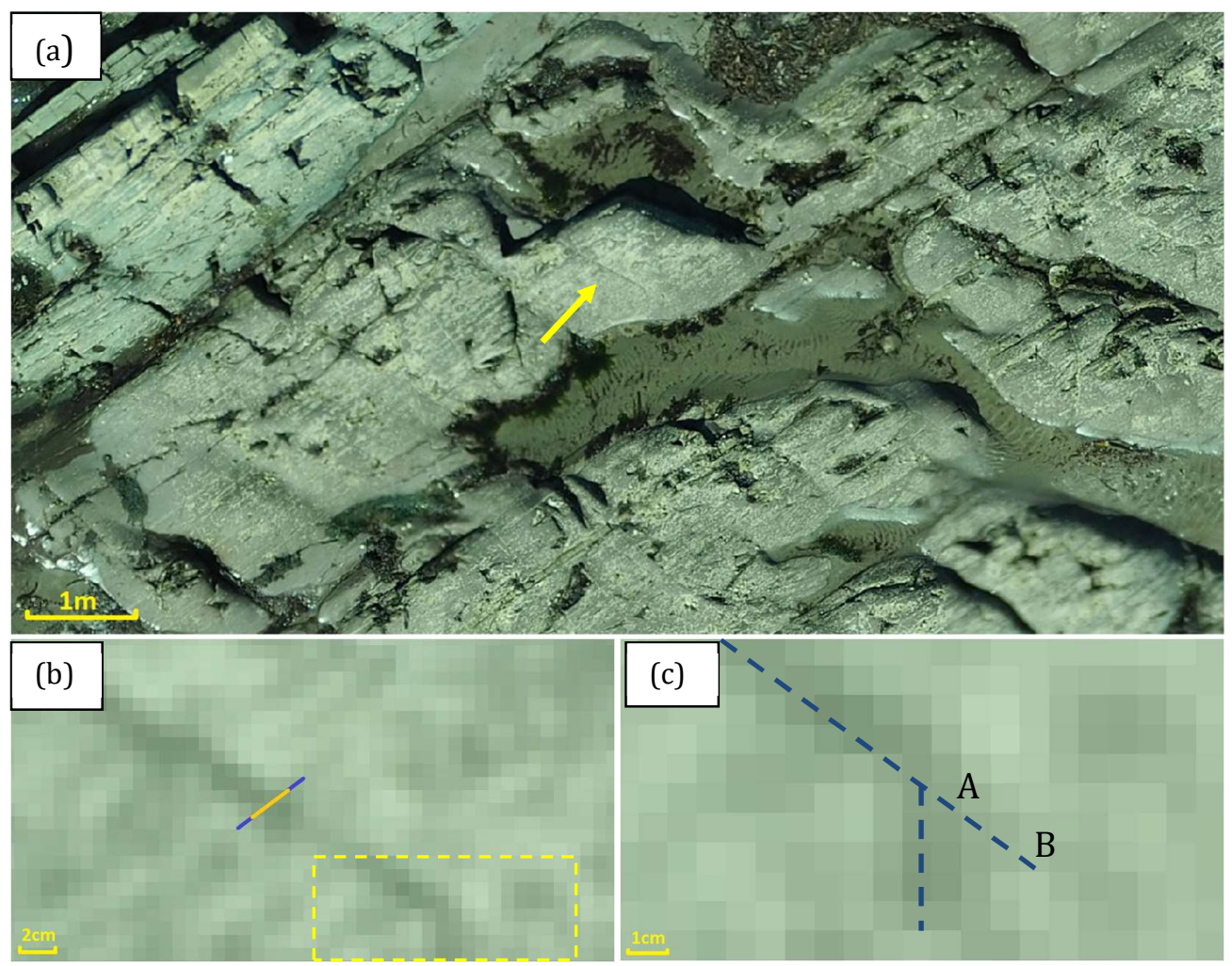

Figure 8 Determination of geometrical characteristics, i.e. length and width, of a joint. (a) zoomed area of the orthomosaic of Figure 5b. The yellow arrow points at the selected joint. (b) Zoom at the right end of the selected joint in (a). The width of the joint could be determined as the length of the yellow line or the length of the yellow and blue lines. (c) Zoomed area included in the rectangle (yellow dashed line in (b)). There is an ambiguity as to where the joint and the splay joint end. 
is very small $(0.8 \mathrm{~cm} /$ pixel for the ZX5), this does not mean that the accuracy that can be achieved is the same. As shown in Figure 8c the width of the joint could be defined as the length of the yellow line $(0.023 \mathrm{~m})$ or the length of both the blue and yellow lines $(0.047 \mathrm{~m})$. The discrepancy is approximately twice the pixel length. For the joint length, the uncertainty is higher: the end of the joint could be defined at any location along the line defined between $\mathrm{A}$ and $\mathrm{B}$ in Figure 8c. The uncertainty here is approximately $24 \mathrm{~mm}$ (i.e. three pixels). The ambiguity in recognizing the edges of faults, fractures and joints is extensively discussed in studies focused on the development of automated recognition algorithms such as that by Kovesi (1999).

\section{DISCUSSION}

This study focused on the optimum use of UAVs for engineering geology projects and presented a structural geological mapping survey as a case study.

\subsection{Comparison with conventional geological mapping surveys}

293 There are two main advantages for the use of a UAV in engineering geological mapping surveys.

294 First, it requires significantly less time and effort to map an area of the same or even much bigger size compared to commonly used mapping techniques. In this study, we focused on an outcrop along the Whitehouse shore that had been mapped before by McCay (2014) using conventional mapping techniques (Figure 9). The smallest area that was surveyed in our study was that obtained by the ZX5. This area is approximately 3 times bigger than the area presented in Figure 9. Yet, it took about a fifth of the time (including the time in the field and the postprocessing time) to produce a structural geological map of the same dimensions and of the same level of detail as that in Figure 9 (personal communication with Alistair McCay on 12/9/2016).

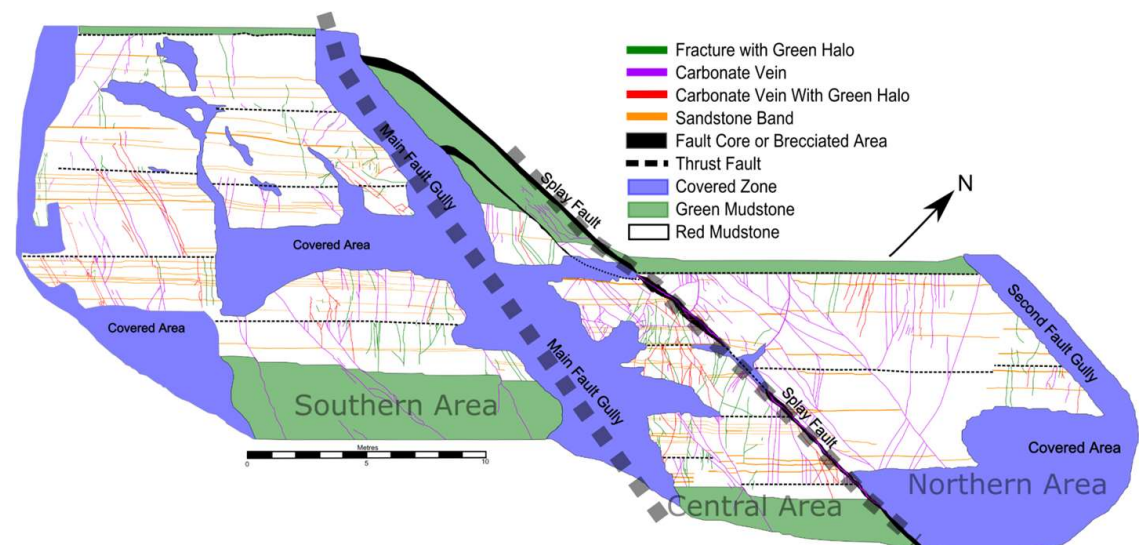

Figure 9 Detailed geological map of the Whitehouse Shore produced based on conventional geological mapping survey techniques (after McCay, 2014) 
302 The second merit of using a UAV for structural geological mapping is that the produced 303 orthomosaic is georeferenced. Where it lacks is the identification and characterization of some 304 structural geological features. Although in our study it was possible to identify the feature type 305 for most of them, there were some for which visual inspection was necessary and no safe 306 conclusions could be made based only on the image. It should be noted that the amount of 307 information that can be extracted from an image also depends on the camera calibration (as discussed in the following paragraph) and the experience of the observer. A more experienced geologist or engineer would be more likely able to identify more feature types on an image compared to those identified by a less experienced person. This number would differ again if using an automated recognition algorithm.

314 We show that for favourable weather conditions such as those prevailed in our study, the achieved resolution of the orthomosaic depends on the flight height and the sensor size and lens. The flight height is restricted by the type of the UAV, i.e. copter or fixed wing, the aviation regulations and the application itself. As shown in Figure 2a the flight height can be increased if using a lens with a bigger focal length or as derived from eq. 1, a bigger sensor size. The last two imply a high resolution camera which, on one hand, might conform with the resolution requirements of a project but on the other, results in increased cost and payload requirements.

321 For a flight height of more than $80 \mathrm{~m}$, a sensor size of 7360 pixels and a $15 \mathrm{~mm}$ lens can achieve a GSD better than $8 \mathrm{~mm} /$ pixel, a value that is adequate for most engineering projects. If a lower height is adopted, for example when using a copter, another factor to be considered is the number of images acquired as it significantly affects the post-processing time. The latter depends on the processing software used and the camera. UASmaster (Trimble Business Centre), the software used for the processing of images in this study, can process 100 images within 1-2 hours. For 1000 images it takes 6 - 8 hours (this includes tasks such as tie point extraction, Ground Control Point (GCP) measurement and camera calibration/exterior orientation-E0) plus 1-2 hours for deliverable creation. For 8000 images the processing time consists of 24-36 hours each for point extraction and GCP measurement/EO and 4-6 hours for deliverable creation. These times refer to an Intel Xeon dual processor @ $2.6 \mathrm{GHz}$ and 48Gb RAM and indicate an almost perfect linear relationship between the number of images and the processing time. It should be noted here that for the same processor and number of images, the 
334 camera also affects the processing time. For example, a 56MP camera will result in a 335 significantly different, i.e. three times higher, number of pixels per image compared to a 16MP 336 camera.

337 The number of ground control points (GCP) can significantly affect the accuracy of the orthomosaic (Tonkin and Mingley, 2016). The number of GCPs required depends on the topography and the method used to establish a GNSS position. For example, post-processing kinematic (PPK) and Real-time kinematic (RTK) only require one GCP. This is the minimum GCP number recommended to allow for the control of the height component of the GNSS measurements. The minimum number in all other cases is at least four or five per flight and their geometrical distribution should be suitable for the site topography (Tonkin and Mingley, 344 2016).

345 GCPs are also used for the calibration of the camera. The calibration of the camera models the 346 lens distortion. In most cases it is also important to calibrate for white balance. The latter does not affect the accuracy of the produced orthomosaic but it affects the true colours of the acquired images, which might be significant for projects related to geological mapping. The calibration of a camera for photogrammetric purposes has been extensively discussed in the international literature, e.g. Zhang, 2000; Wang et al., 2008; Balletti et al. 2014.

\subsection{User errors}

As with every other technology, UAVs require sensible use. In many cases, the result of a UAV survey reflects user errors. One of the parameters that are controlled by the user and affect the quality of the orthomosaic is the forward and side overlap. The recommended value for the

355 forward and side overlap is at least $80 \%$ for mapping surveys that require high accuracy 356 (Gatewing, 2013). This might not be always achievable if the shutter speed of the camera is too 357 slow for the chosen flight height and UAV speed. Also it can be compromised by not anticipating the effects of topography and the UAV orientation overlap. An example of the effect of topography on the overlap value is shown in Figure 10. Figure 10a shows the orthomosaic of a hill area. The black spots visible at the top left of the image are areas that lacked sufficient tie points (i.e. common points among the images) for the images to be tied together. That particular area of the orthomosaic should depict a hill. Figure 10b shows the point cloud focusing on that

363 hill. It is rotated so that the noise in the point cloud corresponding to the black spots in the orthomosaic (Figure 10a) is apparent. In this case the overlap that was chosen by the user was 

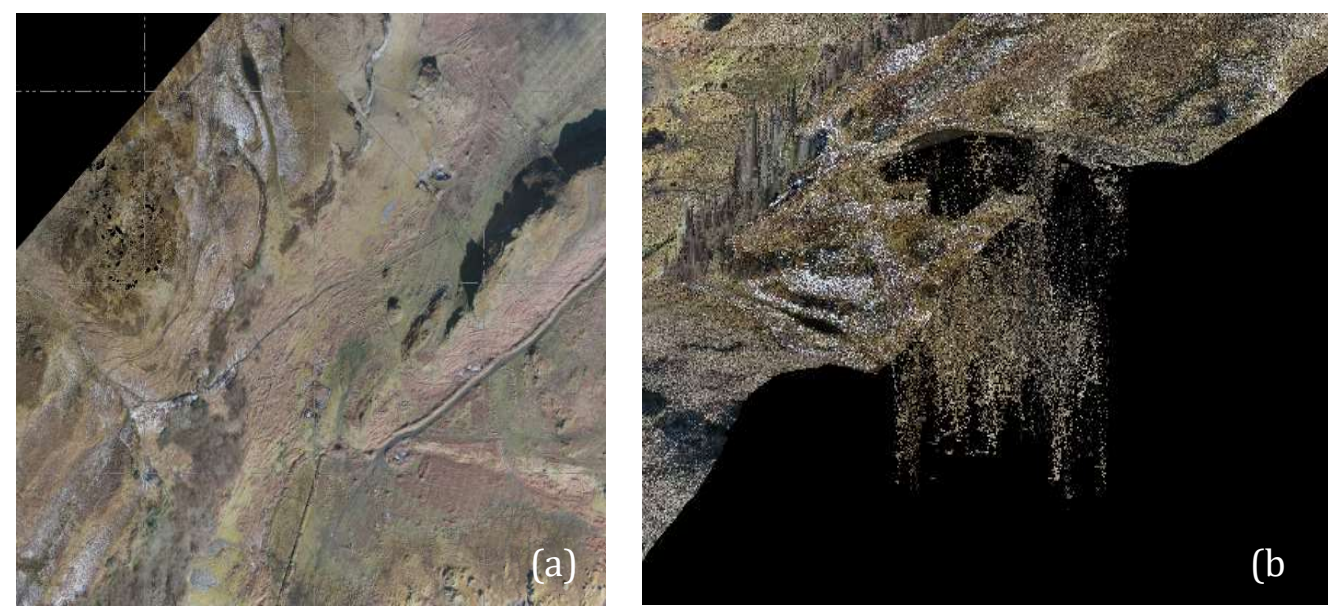

Figure 10 Effect of poor overlap on the orthomosaic. (a) orthomosaic of a hill area. The black spots at the top left are due to poor overlap. As a result the top of the hill is missing. (b) Point cloud of the area where the black spots in (a) appear. The result is noise. Images courtesy of Survey Solutions Scotland Ltd.

and the take off point was not at the top of the hill but approximately at mid height. As a result,

367 the effective overlap value for the area close to the top of the hill was much smaller (see Figure 368 11a) than $85 \%$.

369 The effect of the UAV orientation and how it compromises the overlap value is shown in Figure 370 11b. The pitch, roll and yaw values are known and provided by the inertial system. They help 371 orientate the images correctly, however, that requires a high standards IMU. Even then, if the 372 image isn't taken in the right orientation, e.g. due to excessive yaw because of unfavourable 373 wind direction, no amount of re-orientation will make the photos overlap.

374 The wind direction is not the only meteorological factor affecting the quality of a UAV survey. A 375 UAV flight should take place in good light conditions. Although the AutoISO can compensate for 376 unfavourable light conditions, this function might be limited in some cameras. A detailed 377 discussion on poor light conditions during a UAV flight and the resulted artefacts on the 378 acquired images is presented in Whitehead and Hugenholtz (2014).
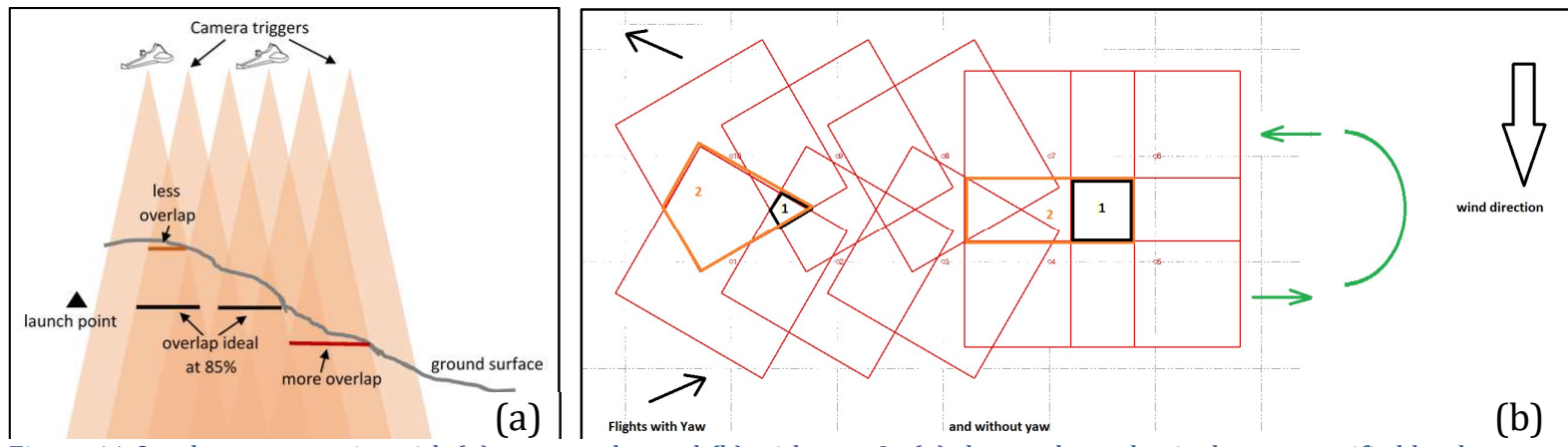

Figure 11 Overlap compromise with (a) topography. and (b) with yaw. In (a) the overlap value is the one specified by the user at the elevation of the launch point. At higher elevations, the effective overlap is less, at lower elevations the effective overlap is more. The change might be significant if the changes in the topography of the surveyed area are major. In (b) the size of the area that is overlapped for two cases, numbered 1 and 2, is shown for the same nominal overlap value for a flight with yaw (b-left) and without (b-right). Figures not in scale. 
Another very common misconception is that the accuracy of measurements based on the images acquired by a UAV survey is equal to the value of the GSD. Our case study has shown that this is not true. The GSD value should be at least half the accuracy required by the project in order to minimize the ambiguity introduced by the pixel colourings as shown in Figure 8. A UAV is a tool and as such it should be used for the right application. For mapping/monitoring of small areas, i.e. less than $10,000 \mathrm{~m}^{2}$, a VTOL (vertical take-off and landing) is more appropriate, while a fixed wing is more suitable for covering larger areas. Figure 12 shows how the survey of a small area, as the one along the Whitehouse shore presented in this paper, is affecting the shape of the flight lines for a fixed wing aircraft. For the fixed wing aircraft (UX5 HP) the flight lines are not strictly straight above the area under survey as would have been in an optimum case (Figure 12a). Instead, they are curved along at least half the length of the area of interest due to the turning circle required by the UX5 HP. This results in images that have a compromised overlap as shown in Figure 11b. On the contrary, Figure 12b shows the flight lines for the ZX5 hexacopter (VTOL) over the same area. In this case, all flight lines are straight and
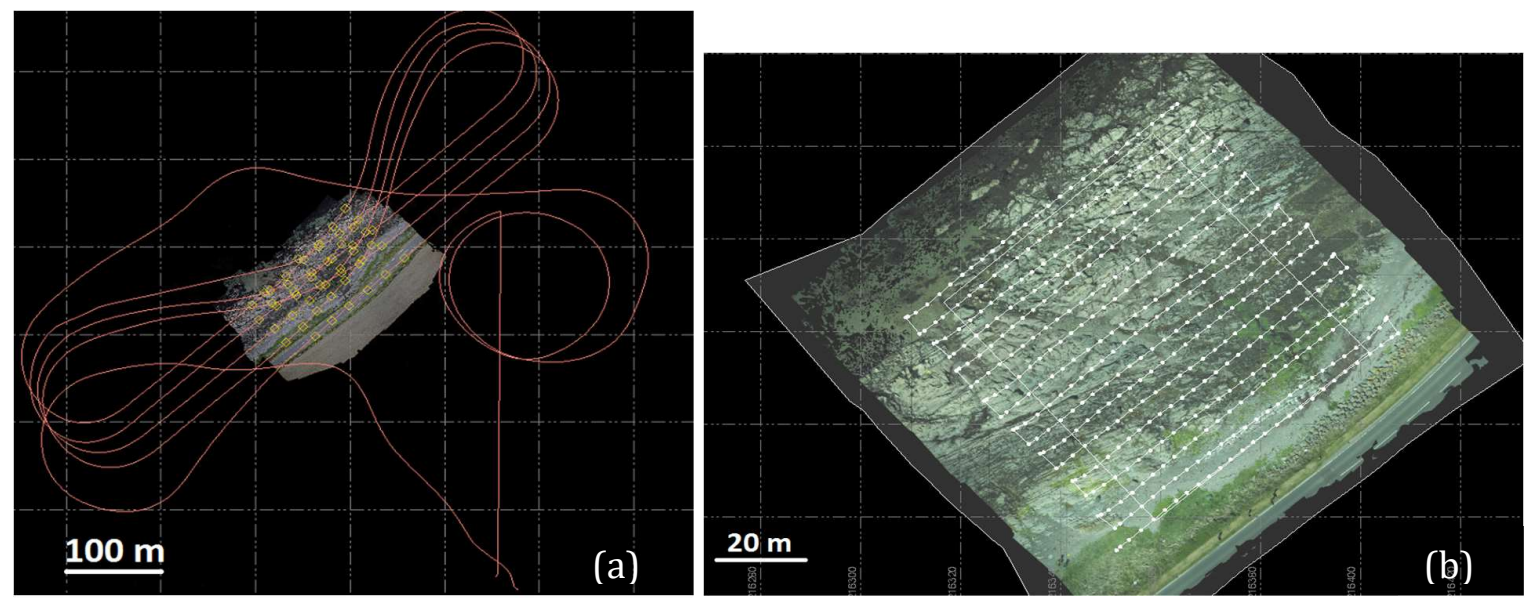

Figure 12 UAV survey at Whitehouse shore. Flight lines for (a) the UX5 HP (red lines) and (b) the ZX5 (white lines). The yellow boxes in (a) and the white dots in (b) indicate the locations where the camera was triggered.

395

396

397

398

399

400

401 parallel.

\section{CONCLUSIONS}

UAVs are a promising technology with great potential as a tool in engineering geology projects. As every tool, it requires sensible use and more importantly, a good understanding of the surveying principles involved. This technology has already become the Holy Grail in mapping surveys, in many cases totally replacing terrestrial surveying equipment: its ability to cover large areas in very little time is a highly desirable characteristic in an era where quick and 
415

effective intervention has become the norm. As shown from this study, this comes with a cost; high resolution images require more expensive sensors or lower flight heights and computers with high processing capacity to allow for processing of large numbers of images. An engineering approach, such as a compromise between the flight height and the detail that can be derived from the orthomosaics, is required almost at all times, if, for example, cost and time are the driving parameters. Due to the wide availability of UAVs and their ease of use, the number of operators with limited surveying and photogrammetric knowledge is constantly increasing. This study offers comprehensive guidance on the consideration of the main technical parameters in order to utilize UAVs to their maximum potential.

\section{ACKNOWLEDGEMENTS}

The authors would like to thank Survey Solutions Scotland Ltd. for providing access to the UX5HP and ZX5 for the needs of this study.

\section{FUNDING SOURCES}

This work was funded by the University of Strathclyde.

\section{REFERENCES}

Ackerman, E. (2011). Japan earthquake: Global Hawk UAV may be Able to Peek Inside Damaged Reactors. Available at: http://spectrum.ieee.org/automaton/robotics/militaryrobots/global-hawk-uav-may-be-able-to-peek-inside-damaged-reactors (Accessed: 8 June 2017).

Balletti, C., Guerra, F., Tsioukas, V., \& Vernier, P. (2014). Calibration of action cameras for photogrammetric purposes. Sensors, 14(9), 17471-17490.

Bemis, S.P., Micklethwaite, S., Turner, D., James, M.R., Akciz, S., Thiele, S.T. and Bangash, H.A. (2014). Ground-based and UAV-based photogrammetry: A multi-scale, high-resolution mapping tool for structural geology and paleoseismology. Journal of Structural Geology, 69, 163-178.

Campbell, J. B., \& Wynne, R. H. (2011). Introduction to remote sensing. Guilford Press.

Cawood, A.J., Bond, C.E., Howell, J.A., Butler, R.W.H. and Totake, Y. (2017). LiDAR, UAV or compass-clinometer? Accuracy, coverage and the effects on structural models. Journal of Structural Geology, 98, 67-82. ISSN 0191-8141, https://doi.org/10.1016/j.jsg.2017.04.004.

Civil Aviation Authority (2016). Air Navigation order. http://www.legislation.gov.uk/uksi/ 2016/765/pdfs/uksi_20160765_en.pdf (accessed on 07/11/2016) 
Colomina, I. and Molina, P. (2014). Unmanned aerial systems for photogrammetry and remote sensing: A review. ISPRS Journal of Photogrammetry and Remote Sensing, 92, 79-97.

Cryderman, C., Mah, S.B. and Shufetoski, A. (2015). Evaluation of UAV photogrammetric accuracy for mapping and earthworks computations. Geomatica, 68 (4), 309-317.

Draeyer, B. and Strecha, C. (2014). White paper: how accurate are UAV surveying methods? Available at: https://support.pix4d.com/entries/40219303-How-accurate-are-UAVsurveying-methods (Accessed: 1 July 2016).

Erickson, E. (2017). Drones help U-M researchers map New Zealand landslides. Available at: http://www.engin.umich.edu/college/about/news/stories/2017/january/landslides (Accessed: 7 June 2017)

Gatewing (2013). Support Bulletin - Image Overlap Settings for Gatewing X100 and Trimble UX5 Aerial Imaging Solutions. Available at: http://surveypartners.trimble.com (Accessed: 12 August 2013).

Greenwood, W., Zekkos, D., Lynch J., Bateman, J., Clark, M., and Chamlagain, D. (2016). UAVBased 3-D Characterization of Rock Masses and Rock Slides in Nepal. 50th US Rock Mechanics/Geomechanics Symposium, American Rock Mechanics Association, Houston, TX, 26-29 June 2016.

Hackney, C. and Clayton, A.I. (2015). Unmanned aerial vehicles (UAVs) and their application in geomorphic mapping. In Clarke, L. and Nield, J.M. (eds.) Geomorphological Techniques. London, GB, British Society for Geomorphology.

He, J., Li, Y. and Zhang, K. (2012). Research of UAV flight planning parameters. Positioning, 3, 43-45.

Jordan, B.R. (2015). A bird's-eye view of geology: The use of micro drones/UAVs in geologic filed work and education. GSA Today, 25 (7), 50-52.

Kovesi, P. (1999). Image Features from Phase Congruency. Journal of Computer Vision Research. $1,1-26$.

Lawson, J. D., \& Weedon, D. S. (Eds.). (1992). Geological Excursions Around Glasgow \& Girvan. Geological Society of Glasgow.

Martínez-Martínez, J., Corbí, H., Martin-Rojas, I., Baeza-Carratalá, J.F. \& Giannetti, A. (2017). Stratigraphy, petrophysical characterization and 3D geological modelling of the historical quarry of Nueva Tabarca island (western Mediterranean): Implications on heritage conservation. Engineering Geology. https://doi.org/10.1016/j.enggeo.2017.10.014. 
468

469

470

471

472

473

474

475

476

477

478

479

480

481

482

483

484

485

486

487

488

489

490

491

492

493

494

495

496

497

498

McCay, A. (2014). Fluid flow through connected sub-seismic features in mudstone. PhD Thesis. University of Strathclyde, Glagow, UK.

Michlethwaite, S., Turner, D, Vasuli, Y., Kovesi, P., Holden, E. J., \& Lucieer, A. (2012). Mapping from an Armchair: rapid, high-resolution mapping using UAV and computer vision technology. In Proceedings of Structural Geology and Resources 2012. Kalgoorlie, Western Australia (130-133).

Niethammer, U., James, M.R., Rothmund, S., Travelletti, J. \& Joswig, A. (2012). UAV-based remote sensing of the Super-Sauze landslide: Evaluation and results. Engineering Geology. 128, 2-11. ISSN 0013-7952, https://doi.org/10.1016/i.enggeo.2011.03.012.

Peng, D., Xu, Q., Liu, F., He, Y., Zhang, S., Qi, X., Zhao, K. \& Zhang, X. (2017). Distribution and failure modes of the landslides in Heitai terrace, China, Engineering Geology. (in press) https://doi.org/10.1016/j.enggeo.2017.09.016.

Raeva, P.I., Filipova, S.L. and Filipov, D.G. (2016). Volume computation of a stockpile-A study case comparing GPS and UAV measurements in an open pit quarry. The International Archives of the Photogrammetry, Remote Sensing and Spatial Information Sciences, XLI-B1, 999-1004.

Remondino, F., Barazzetti, L., Nex, F., Scaioni, M. and Sarazzi, D. (2011). UAV photogrammetry for mapping and 3D modeling-current status and future perspectives. The International Archives of the Photogrammetry, Remote Sensing and Spatial Information Sciences, XXXVIII1/C22, 25-31.

Siebert, S. and Teizer, J. (2014). Mobile 3D mapping for surveying earthwork projects using an Unmanned Aerial Vehicle (UAV) system. Automation in Construction, 41, 1-14.

Strecha, C., von Hansen, C., Gool, L.V., Fua, P., Thoennessen, U. (2008). On Benchmarking Camera Calibration and Multi-View Stereo for High Resolution Imagery. In Proceedings of the IEEE Computer Society Conference on Computer Vision and Pattern Recognition, Anchorage, AK, USA, 24-26 June 2008.

Stumpf, A., Malet, J. P., Kerle, N., Niethammer, U., \& Rothmund, S. (2013). Image-based mapping of surface fissures for the investigation of landslide dynamics. Geomorphology, 186, 12-27.

Tannant, D.D., Giordan, D. \& Morgenroth, J. (2017). Characterization and analysis of a translational rockslide on a stepped-planar slip surface. Engineering Geology. 220, 144-151. ISSN 0013-7952, https://doi.org/10.1016/j.enggeo.2017.02.004. 
Tonkin, T. N., \& Midgley, N. G. (2016). Ground-Control Networks for Image Based Surface

500 Reconstruction: An Investigation of Optimum Survey Designs Using UAV Derived Imagery

501 and Structure-from-Motion Photogrammetry. Remote Sensing, 8(9), 786.

502 Vasuki, Y., Holden, E.J., Kovesi, P. and Michklethwaite, S. (2014). Semi-automatic mapping of

503 geological Structures using UAV-based photogrammetric data: An image analysis approach.

$504 \quad$ Computers and Geosciences, 69, 22-32.

505 Wang, J., Shi, F., Zhang, J., \& Liu, Y. (2008). A new calibration model of camera lens 506 distortion. Pattern Recognition, 41(2), 607-615.

507 Watts, A. C., Ambrosia, V. G., \& Hinkley, E. A. (2012). Unmanned aircraft systems in remote 508 sensing and scientific research: Classification and considerations of use. Remote $509 \quad$ Sensing, 4(6), 1671-1692.

510 Whitehead, K., \& Hugenholtz, C. H. (2014). Remote sensing of the environment with small 511 unmanned aircraft systems (UASs), part 1: A review of progress and challenges 1. Journal of 512 Unmanned Vehicle Systems, 2(3), 69-85.

513 Zhang, Z. (2000). A flexible new technique for camera calibration. IEEE Transactions on pattern $514 \quad$ analysis and machine intelligence, 22(11), 1330-1334. 